\title{
Who Benefits Most From Using Social Media, the Socially Rich or the Socially Poor?
}

\author{
J. Loes Pouwels ${ }^{\mathrm{a}, \mathrm{b}}$, Loes Keijsers ${ }^{\mathrm{c}}$, Candice Odgers ${ }^{\mathrm{d}, \mathrm{e}}$
}

aBehavioural Science Institute, Radboud University, Nijmegen, The Netherlands ${ }^{\mathrm{b}}$ Amsterdam School of Communication Research, University of Amsterdam, The Netherlands

${ }^{\mathrm{c}}$ Department of Psychology, Education \& Child Studies, Erasmus University, Rotterdam, The Netherlands

${ }^{\mathrm{d} D e p a r t m e n t}$ of Psychiatry and Behavioral Sciences, Duke University, Durham, North Carolina

${ }^{\text {e}}$ Department of Psychological Science, University of California, Irvine, Irvine

Draft version 2, April 192022.

This paper has been published in Current Opinion in Psychology as:

Pouwels, J.L., Keijsers, L., \& Odgers, C. (2022). Who benefits most from using social media, the socially rich or the socially poor? Current Opinion in Psychology, 101351.

https://doi.org/10.1016/j.copsyc.2022.101351

This is not the copy of record and may not exactly replicate the final, authoritative version of the article. The published article is available on: https://doi.org/10.1016/j.copsyc.2022.101351

ORCID IDs: J. Loes Pouwels (D) https://orcid.org/0000-0002-9586-392X; Loes Keijsers https://orcid.org/0000-0001-8580-6000; Candice Odgers (D) https://orcid.org/ 0000-0003-4937-6618

Corresponding author: J. Loes Pouwels, loes.pouwels@,ru.nl; Postal address: J. Loes Pouwels, Behavioural Science Institute, Radboud University, Postbus 9104, $6500 \mathrm{HE}$ Nijmegen, The Netherlands.

Disclosure of interest: No competing interests 


\begin{abstract}
Research has shown that some individuals benefit from using social media because it may help them to obtain social capital. This article questions who are most likely to benefit: the socially rich (i.e., individuals with a preference for social interaction, support, or without interpersonal problems) or the socially poor? It is hard to provide a definite answer to this question: Previous empirical studies have yielded mixed findings and were difficult to compare due to varying conceptualizations and analytic approaches. To better understand the complex interplay between individuals' social media use and social capital, we discuss the added value of within-person analyses and person-specific designs.
\end{abstract}

Keywords. Social Network Site Use (SNS use), psychosocial functioning, rich-get-richer hypothesis, poor-get-richer hypothesis, heterogeneity 


\section{Introduction}

The rapid rise of social media use in today's society is paralleled by an equally rapid rise in public concerns regarding potential harmful effects. Likewise, empirical studies focused on whether social media use negatively affects individuals' well-being have increased in the past years [1-5]. Overall, research has shown that associations between social media use and subsequent changes in well-being, such as happiness and depression, are non-existent to small [6-8]. Some studies even suggest that social media use may be beneficial because it promotes social resilience factors that may protect people against decreases in well-being [9]. Meta-analyses [10-12] and reviews [13-16], for instance, suggest that those adolescents and adults who use social media use to a greater extent have higher levels of social capital in terms of stronger links with acquaintances and friends [17].

One unanswered question is which individuals are likely to benefit most from using social media. Who attains social capital, who builds close relationships, and who receives social support while using social media? Currently, two hypotheses are typically juxtaposed: the socially rich-get-richer (or social enhancement) hypothesis versus the poor-get-richer (or social compensation) hypothesis. We review empirical evidence for these hypotheses by focusing on three types of indicators of social richness and poorness. These indicators tap into the preference of social interactions (i.e., extraversion and introversion), problems in interpersonal relationships (i.e., loneliness and social anxiety), and social support [18, 19]. Individuals with a preference for social interactions, with support, or without interpersonal problems are considered as socially rich. Those without a preference of social interactions, without support, or with interpersonal problems are defined as socially poor. After providing an overview of the literature, we present a roadmap for future research. We argue that study designs should be adapted to recent theoretical insights that media effects (a) take place within persons and (b) that these intra-individual effects may also differ from person to person. As such, we argue that certain socially rich and certain socially poor individuals may get richer due to their social media use, whereas others may get poorer.

\section{The Rich-Get-Richer and Poor-Get-Richer Hypotheses}

Social media, such as Instagram, Facebook, Snapchat, and TikTok have been defined as all "computer-mediated communication channels that allow users to interact with narrow and broad audiences in real time or asynchronously" [20]. Social media offer the opportunity to stay in almost constant touch with friends and family [21, 22]. This accessibility of social media forms the basis of the rich-get-richer hypothesis: Individuals who already have a rich offline social network are particularly likely to use social media as an avenue to further strengthen their social capital by offering additional supports online [23, 24]. The rich-getricher hypothesis therefore states that individuals with the highest existing levels of support, a preference for social interactions, and without problems in social relationships would benefit most.

In contrast, according to the poor-get-richer hypothesis, socially poor individuals, who may have the most to gain from online interactions, should benefit the most from social media use in terms of (online) social capital. Social media conversations are asynchronous, which means that users do not have to respond directly [25]. Moreover, text-based interactions contain less cues such as voice or audio than real-live conversations. Via social media, individuals therefore have increased control over what, when, and how they disclose information $[25,26]$. The hyperpersonal communication theory describes that these features of social media help individuals to optimize their self-presentation [27]. The poor-get-richer hypothesis therefore states that especially "socially poor" individuals may feel more at ease to disclose intimate personal information in online contexts than in offline contexts. This online self-disclosure may, in turn, enhance their social capital and compensate for the lack of indepth relationships in their offline social lives [26, 28-30]. 
3. Empirical evidence for the rich-get-richer and poor-get-richer hypotheses

Although the number of studies on social media have exploded in the past years, surprisingly little research has examined the rich-get-richer and poor-get-richer hypotheses. Among those that have examined these hypotheses, findings have been mixed. For example, in one of the first studies during the early days of internet, Kraut et al [19] examined whether the association between internet use and changes in social capital across six months (i.e., community involvement and family communication) was moderated by adolescents' and adults' social richness (i.e., extraversion and high social support) and poorness (i.e., introversion and low support). In line with the rich-get-richer hypothesis, they found that internet use was related to increased social capital among extraverted and supported individuals and to decreased capital among introverted and unsupported individuals.

Further support for this hypothesis was found by Cheng et al. [18] who synthesized 161 studies on the associations between adolescents' and adults' social richness and poorness (i.e., extraversion, social anxiety and loneliness) and online social capital (i.e. material or immaterial resources that individuals obtain from their online social connections). In support of the rich-get-richer hypothesis, their meta-analysis revealed that extraverted individuals $(r=$ $.21)$ and those low in loneliness $(r=.22)$ had higher levels of online social capital than nonextraverted and lonely individuals. No positive association between social anxiety and online social capital was found, which would have supported the poor-get-richer hypothesis.

Other studies, however, have supported the poor-get-richer hypothesis. For example, a cross-sectional mediation analysis revealed that greater perceptions of the breadth and depth of online communication among socially anxious (i.e., socially poor) versus non-anxious adolescents were related to an increased tendency to use online communication and higher levels of friendship closeness [31]. Likewise, longitudinal research revealed that especially among poor (i.e., shy) adolescents, having online exclusive friendships increased the likelihood to form conjoint and offline-exclusive friendships eight months later [32].

To further increase the complexity, findings from another study pointed at both a poorget-richer and poor-get-poorer effect [33]. Specifically, longitudinal analyses of a two-wave panel study showed that socially poor adolescents (i.e. high on loneliness) were particularly likely to use social media in both active and passive ways. A poor-get-poorer effect was found given that passive social media use was related to decreased social support. However, they also found a poor-get-richer effect given that active Facebook use was related to increased social support.

Taken together, a definite answer to the question of whether the socially rich or the poor benefit most from social media remains largely unanswered. An ill-defined mix of conceptualizations and analytical approaches have been used to test the hypotheses. Specifically, studies differed in their operationalizations of richness, poorness, and social capital and used different analytical approaches (e.g., linear regression; mediation; moderation) to analyze their cross-sectional or longitudinal data. Thus, similar to recent narrative reviews [34-38], we are unable to reach an overall conclusion and, instead, conclude that more aligned research approaches are required. One way to investigate the rich-get-richer and poor-get-richer hypotheses in a more systematic way could be to adapt the design of studies to the most recent insights in theories of development and media effects.

\section{A roadmap for future research on the rich-get-richer and poor-get-richer hypotheses.}

Theories of development and media effects assume that social media may cause changes in social capital (i.e., getting richer) at the individual level, hence, these mechanisms take place within persons [e.g., 39, 40]. Second, these 'media effects' vary from individual to individual [39]. These more recent theoretical insights have important implications for how we study the rich-get-richer and poor-get-richer hypotheses. In the next section, we first review the evidence for these insights and explain how methodological advancements offer 
new possibilities for examining the rich-get-richer and poor-get-richer hypotheses.

\subsection{A within-person perspective on the rich-get-richer and poor-get-richer hypotheses.}

Recently, social media researchers have stressed the need to conceptualize effects of social media as a within-person phenomenon $[39,40]$. For example, it may be that adolescents feel lower levels of social support than they would typically do after passively using social media and higher levels of support after actively using social media [33]. To unravel whether and when adolescents get richer over time, it is important to get insight in such within-person social media effects on social capital. Assessing how individuals fluctuate in social capital and whether this is linked to their social media use [41, 42] can be done with daily diaries, experience sampling studies, within-person experiments, observation research, or longer-term longitudinal studies [41, 43, 44]. One of the unique features of such designs is the possibility to disentangle within-person variance from between-person variance (see Figure 1a and Figure 1b). For example, an experience sampling methodology (ESM) study examined social media use and social capital (i.e., friendship closeness) multiple times per day [45]. Although adolescents who used social media to a greater extent than their peers felt themselves on average closer to their friends (i.e., positive between person association), adolescents felt less close when they used social media in the previous hour than when they did not use social media (i.e., negative within-person association). Hence, the group-level between-person association was positive, but the actual media-effect was negative.

Even though many social media scholars stress the added value of within-person studies [46-48], the majority of research on the rich-get-richer hypothesis has still relied on between-person associations of social media use with (online) social capital. This research is well-suited to understand the extent to which individual differences in social capital and social media use are related. However, gaining insight in the "getting richer" part of the hypotheses requires examination of the effect of social media use on intra-individual changes in social capital over time. As such, the question "Do individuals actually get richer at the short-and longer-term due to using social media?" requires insights at the within-person levels, which is currently not yet common. Such within-person insights could be combined with betweenperson insights to reveal to what extent the within-person effects of social media use on social capital depend on individual dispositions such as indicators of social richness and poorness.

\subsection{A person-specific perspective on the rich-get-richer and poor-get-richer hypotheses.}

A second critical concern with existing survey method studies is that, even when they were within-person, they predominantly derived one average effect for the population or subpopulation of socially rich versus poor individuals. However, without an actual test of heterogeneity within subgroups, the implicit methodological assumption is that there is a homogeneous set of social media effects across all socially rich and poor individuals [8]. This is assumption is unlikely to hold. Like other complex forms of human behavior, the interplay between social media and social capital is heterogeneous [43] - while one socially rich person may benefit another may be harmed. Modern theories on development, such as the differential susceptibility to media effects model [49] and ecological theories of development [50], both propose that a unique combination of dispositional, developmental, and socio-contextual characteristics determines a person's own unique responses to social media use, which may vary over time. Even seemingly homogeneous groups of socially rich or poor individuals vary on different indicators of social richness and poorness as well as other dispositional, developmental and contextual variables, and so do their experienced social media effects [45]. For example, lonely individuals (who are often considered as socially poor) differ from each other in their preference for social interactions and the amount of social support that they receive. Assuming that an overall effect may hold for all socially rich and poor adolescents within a subgroup may therefore lead to one-size-fits-all fallacies [44].

Acknowledging causal effect heterogeneity [44] - the idea that every individual may 
be uniquely affected by using social media - leads us to abandon the debate whether the average socially rich or the average socially poor person benefits most. Both hypotheses may be true, yet only for certain (socially rich and poor) individuals. Instead of juxtaposing the hypotheses, this idea encourages us to examine to what extent the apparently homogenous groups of socially rich and poor individuals are heterogeneous by embracing a more nuanced type of question: Which socially rich and poor individuals benefit from using social media in terms of social capital and which do not? Answering this question warrants that we obtain closer insights in the extent to which overall effect sizes per (sub)group are applicable to the experiences of one single individual within that group based on within-person experiments or intensive longitudinal data collections [43, 51, 52].

One possible design is to test how effects differ from one person to another is to analyze person-specific $(N=1)$ effects first before they are aggregated [39]. After having identified those who benefit and those who does not (see Figure 1c), both groups could be compared on a wide range of indicators of social richness and poorness (see Figure 1d) as well as other relevant constructs (e.g., type of social media use or developmental stage). This so-called bottom-up approach [39] could help to identify how many socially rich or poor individuals respond in a certain way. It also helps to acknowledge that individuals could be rich according to certain indicators but poor according to others. Although it should be noted that person-specific approaches have recently been criticized for their lack of generalizability [53] (for a detailed response to this critique, see Valkenburg, 2022 [54]), they are often combined with analyses at the aggregated level to unify the strengths of both types of knowledge [52].

\section{Conclusion}

By reviewing existing empirical work on the rich-get-richer and poor-get-richer hypotheses, we found mixed findings. Whereas some studies found that the rich got richer, others suggest that the poor got richer. Here we postulate that the answer may differ per individual, as well as across developmental stage and context. We propose that future research on the rich-get-richer and poor-get-richer hypotheses could help us to move from subgroup insights to individual level understanding. Whereas some effects may be universal, obtaining insights into person-specific patterns may help us to better tailor social media prevention and intervention programs to the needs of individuals. Such findings could also identify those (socially rich and poor) individuals who are in need of intervention and provide them with person-specific supports.

\section{Author Contributions}

J. Loes Pouwels: Conceptualization, Writing - First draft preparation, Loes Keijsers: Conceptualization, Writing - Reviewing and Editing, Candice Odgers: Conceptualization, Writing - Reviewing and Editing.

\section{Funding}

This study was funded by an NWO Spinoza Prize awarded to Patti M. Valkenburg by the Dutch Research Council (NWO). Additional funding was received from a VIDI grant (NWO VIDI Grant 452.17.011) awarded to Loes Keijsers. Candice Odgers is supported by the Jacobs Foundation and the Canadian Institute for Advanced Research. The funder had no involvement in the study.

\section{References}

1. J.L. Pouwels, P.M. Valkenburg, I. Beyens, I.I. van Driel, L. Keijsers, Social media use and friendship closeness in adolescents' daily lives: An experience sampling study, 
Developmental Psychology 57(2) (2021) 309-323.

https://doi.org/10.1037/dev0001148

2. G. Aalbers, R.J. McNally, A. Heeren, S. de Wit, E.I. Fried, Social media and depression symptoms: A network perspective, Journal of Experimental Psychology 148(8) (2019) 1454-1462. https://doi.org/10.1037/xge0000528

3. M. Jensen, M.J. George, M.R. Russell, C.L. Odgers, Young adolescents' digital technology use and mental health symptoms: Little evidence of longitudinal or daily linkages, Clinical Psychological Science 7(6) (2019) 1416-1433.

https://doi.org/10.1177/2167702619859336

4. S.M. Coyne, A.A. Rogers, J.D. Zurcher, L. Stockdale, M. Booth, Does time spent using social media impact mental health? An eight year longitudinal study, Computers in Human Behavior 104 (2020) Article 106160.

https://doi.org/10.1016/j.chb.2019.106160

5. I. Beyens, J.L. Pouwels, I.I. van Driel, L. Keijsers, P.M. Valkenburg, The effect of social media on well-being differs from adolescent to adolescent, Scientific Reports 10 (2020) 10763. https://doi.org/10.1038/s41598-020-67727-7

6. P.M. Valkenburg, A. Meier, I. Beyens, The effects of social media use on adolescents' mental health: An umbrella review, Current Opinion in Psychology (2021). https://doi.org/10.1016/j.copsyc.2021.08.017

7. A. Meier, L. Reinecke, Social media and mental health: Reviewing effects on eudaimonic well-being, in: R.L.N.J.G. Myrick. (Ed.), Our online emotional selves: The link between digital media and emotional experience (2021). https://doi.org/10.31234/osf.io/xvts8

8. P.M. Valkenburg, The effects of social media use on adult well-being and ill-being: What we know and what we need to know, PsyArxiv (2021).

https://doi.org/10.31234/osf.io/nxq8j

* This is a rigourous umbrella review that provides an overview of the state-of-the art insights regarding the effects of social media use on adults' well-being and ill-being. By integrating the findings of more than 40 meta-analyses and reviews, it concluded that findings of previous studies were inconsistent. To shed light on this inconsistency, this study calls for the implementation of a causal effect heterogeneity paradigm in our future research.

9. A. Meier, L. Reinecke, Computer-mediated communication, social media, and mental health: A conceptual and empirical meta-review, Communication Research 48 (2021) 1182-1209. https://doi.org/10.1177/0093650220958224

10. D. Liu, S.E. Ainsworth, and R.F. Baumeister, A meta-analysis of social networking online and social capital, Review of General Psychology, 20(4) (2016) 369-391. https://doi.org/10.1037/gpr0000091

11. D. Liu., K.B. Wright, and B. Hu, A meta-analysis of social network site use and social support, Computers \& Education 127 (2018) 201-213.

https://doi.org/10.1016/j.compedu.2018.08.024

12. E. Domahidi, The associations between online media use and users' perceived social resources: A meta-analysis, Journal of Computer-Mediated Communication 23(4) (2018) 181-200. https://doi.org/10.1093/jcmc/zmy007

13. Y.T. Uhls, N.B. Ellison, and K. Subrahmanyam, Benefits and costs of social media in adolescence. Pediatrics 140 (2017) S67. https://doi.org/10.1542/peds.2016-1758E

14. P.M. Valkenburg, and J. Peter, Online communication among adolescents: An integrated model of its attraction, opportunities, and risks. Journal of Adolescent Health 48(2) (2011) 121-127. https://doi.org/10.1016/j.jadohealth.2010.08.020 
15. J.C. Yau, and S.M. Reich, Are the qualities of adolescents' offline friendships present in digital interactions?, Adolescent Research Review 3(3) (2018) 339-355.

https://doi.org/10.1007/s40894-017-0059-y

16. S.H., Taylor, P. Zhao, and N.N. Bazarova, Social media and close relationships: a puzzle of connection and disconnection, Current Opinion in Psychology, 45, (2022), 101292. https://doi.org/10.1016/j.copsyc.2021.12.004

17. R.D. Putnam, and K. Goss, A., Introduction, in Democracies in flux: The evolution of social capital in contemporary society, R.D. Putnam, Editor. 2002, Oxford University Press.

18. C. Cheng, H.-Y. Wang, L. Sigerson, C.-L. Chau, Do the socially rich get richer? A nuanced perspective on social network site use and online social capital accrual, Psychological Bulletin 145(7) (2019) 734-764. https://doi.org/10.1037/bul0000198 ** This is one of the most comprehensive studies on the rich-get-richer and poor-getricher hypotheses with a strong theoretical framework. It synthesized 161 crosssectional studies of adolescents' and adults' social richness and poorness (i.e., extraversion, social anxiety and loneliness) with online social capital (i.e. material or immaterial resources that individuals obtain from their online social connections). This synthesis provided more evidence for the rich-get-richer than for the poor-get-richer hypothesis.

19. R. Kraut, et al., Internet paradox revisited, Journal of Social Issues 58(1) (2002) 49-74.

20. J.B. Bayer, P. Triệu, N.B. Ellison, Social media elements, ecologies, and effects, Annual Review of Psychology 71 (2020) 471-497. https://doi.org/10.1146/annurevpsych-010419-050944

21. d. boyd, It's complicated: The social lives of networked teens, Yale University Press, New Haven, CN, 2014.

22. P.M. Valkenburg, J.T. Piotrowski, Plugged in: How media attract and affect youth, Yale University Press, New Haven, NJ, 2017.

23. A. Rousseau, E. Frison, S. Eggermont, The reciprocal relations between Facebook relationship maintenance behaviors and adolescents' closeness to friends, Journal of Adolescence 76 (2019) 173-184. https://doi.org/10.1016/j.adolescence.2019.09.001

24. D. Buhrmester, W. Furman, M.T. Wittenberg, H.T. Reis, Five domains of interpersonal competence in peer relationships, Journal of Personality and Social Psychology 55(6) (1988) 991-1008. https://doi.org/10.1037/0022-3514.55.6.991

25. M.V., Vanden Abeele, A.P. Schouten, and M.L. Antheunis, Personal, editable, and always accessible: An affordance approach to the relationship between adolescents' mobile messaging behavior and their friendship quality. Journal of Social and Personal Relationships 34(6) (2017) 875-893. https://doi.org/10.1177/0265407516660636

26. A.P. Schouten, P.M. Valkenburg, J. Peter, Precursors and underlying processes of adolescents' online self-disclosure: Developing and testing an "Internet-attributeperception" model, Media Psychology 10(2) (2007) 292-314. https://doi.org/10.1080/15213260701375686

27. J.B. Walther, Computer-mediated communication: Impersonal, interpersonal, and hyperpersonal interaction, Communication Research 23(1) (1996) 3-43. https://doi.org/10.1177/009365096023001001

28. K.Y.A. McKenna, J.A. Bargh, Causes and consequences of social interaction on the internet. A conceptual framework, Media Psychology 1(3) (1999) 249-269. https://doi.org/10.1207/s1532785xmep0103 4

29. J. Nesi, S. Choukas-Bradley, M.J. Prinstein, Transformation of adolescent peer relations in the social media context: Part $1-$ A theoretical framework and application 
to dyadic peer relationships, Clinical Child and Family Psychology Review 21(3) (2018) 267-294. https://doi.org/10.1007/s10567-018-0261-x

30. R. Nowland, E.A. Necka, J.T. Cacioppo, Loneliness and social internet use: Pathways to reconnection in a digital world?, Perspectives on Psychological Science 13(1) (2017) 70-87. https://doi.org/10.1177/1745691617713052

31. P.M. Valkenburg, and J. Peter, Preadolescents' and adolescents' online communication and their closeness to friends, Developmental Psychology 43(2) (2007) 267-277. https://doi.org/10.1037/0012-1649.43.2.267

32. M.H.W., van Zalk, et al., Influences between online-exclusive, conjoint and offlineexclusive friendship networks: The moderating role of shyness. European Journal of Personality 28(2) (2014) 134-146. https://doi.org/10.1002/per.1895

33. E. Frison, and S. Eggermont, Toward an integrated and differential approach to the relationships between loneliness, different types of Facebook use, and adolescents' depressed mood. Communication Research 47(5) (2020) 701-728. https://doi.org/10.1177/0093650215617506

* This longitudinal empirical study on the rich-get-richer and poor-get-richer consisted of a two-wave panel study among 1,612 adolescents. It revealed that the type of social media use matters, given that active Facebook use was related to a poor-get-richer effect and passive Facebook use to a poor-get-poorer effect.

34. R. Dredge, L. Schreurs, Social media use and offline interpersonal outcomes during youth: A systematic literature review, Mass Communication and Society 23(6) (2020) 885-911. https://doi.org/10.1080/15205436.2020.1810277

35. M. Luo, J.T. Hancock, Self-disclosure and social media: motivations, mechanisms and psychological well-being, Current Opinion in Psychology 31 (2020) 110-115. https://doi.org/10.1016/j.copsyc.2019.08.019

36. S. Negriff, K. Subrahmanyam, Is online peer engagement bad for all youth all of the time? The benefits and perils of online peer interactions, in: N. van Zalk, C.P. Monks (Eds.), Online peer engagement in adolescence: Positive and negative aspects of social interactions, Routledge, London, 2020.

37. B.H. Schneider, Y. Amichai-Hamburger, A. Lonigro, Adolescent online friendships: Do the rich or the poor get richer?, in: N. van Zalk, C.P. Monks (Eds.), Online peer engagement in adolescence: Positive and negative aspects of social interactions, Routledge, London, 2020.

38. D. Smith, T. Leonis, S. Anandavalli, Belonging and loneliness in cyberspace: impacts of social media on adolescents' well-being, Australian Journal of Psychology 73(1) (2021) 12-23. https://doi.org/10.1080/00049530.2021.1898914

39. P.C.M. Molenaar, C.G. Campbell, The new person-specific paradigm in psychology, Current Directions in Psychological Science 18(2) (2009) 112-117.

https://doi.org/10.1111/j.1467-8721.2009.01619.x

40. P.M. Valkenburg, J. Peter, J.B. Walther, Media effects: Theory and research, Annual Review of Psychology 67 (2016) 315-338. https://doi.org/10.1146/annurev-psych122414-033608

41. N. Griffioen, M.v. Rooij, A. Lichtwarck-Aschoff, I. Granic, Toward improved methods in social media research, Technology, Mind, and Behavior 1 (2020). https://doi.org/10.1037/tmb0000005

* This article describes concrete improvements of methods in social media use research. Amongst others, it introduces the stimulated recall method, an exciting novel methodology that consists of interviews regarding how participants use their smartphone, with the use of a video recording of their phone use and participants' own phone to stimulate recall of events. This method could provide novel insights in the 
great diversity in how young people use social media and what their underlying motivations are.

42. A. Orben, Teenagers, screens and social media: A narrative review of reviews and key studies, Social Psychiatry and Psychiatric Epidemiology 55 (2020) 407-414. https://doi.org/10.1007/s00127-019-01825-4

43. N. Bolger, K. Zee, M. Rossignac-Milon, R. Hassin, Causal processes in psychology are heterogeneous, Journal of Experimental Psychology: General, 148 (2019) 601-618. https://doi.org/10.1037/xge0000558

* This study provides empirical evidence for the idea that causal processes in psychology are heterogeneous. It offers very concrete guidelines with regard to how causal effect heterogeneity could be examined with experimental repeated measures designs.

44. L. Keijsers, E. van Roekel, Longitudinal methods in adolescent psychology: Where could we go from here? And should we?, in: L.B. Hendry, M. Kloep (Eds.), Reframing adolescent research, Routledge, New York, NY, 2019, pp. 56-77.

45. J.L. Pouwels, P.M. Valkenburg, I. Beyens, I.I. van Driel, L. Keijsers, Some socially poor but also some socially rich adolescents feel closer to their friends after using social media, Scientific Reports (in press). https://doi.org/10.31234/osf.io/mdfzj ** This is the first study on the rich-get-richer and poor-get-richer hypotheses that incorporated a state-of-the-art measurement burst design, consisting of closely spaced ESM assesment and longer-term bi-weekly follow-up assesments. It revealed that even within subgroups of socially rich or socially poor individuals, there may be some who benefit and some who do not. Moreover, it found that short-term effects of social media use on friendship closeness may differ, or even be opposing, from longer-term effects.

46. A., Orben, T. Dienlin, and A.K. Przybylski, Social media's enduring effect on adolescent life satisfaction, Proceedings of the National Academy of Sciences, 116(21) (2019) 10226-10228. https://doi.org/10.1073/pnas.1902058116

47. M. Jensen, et al., Does adolescent digital technology use detract from the parentadolescent relationship? Journal of Research on Adolescence, 31(2) (2021) p. 469481. https://doi.org/10.1111/jora.12618

48. M.J. Prinstein, J. Nesi, and E.H. Telzer, Commentary: An updated agenda for the study of digital media use and adolescent development - future directions following Odgers \& Jensen (2020). Journal of Child Psychology and Psychiatry, 61(3) (2020) 349-352. https://doi.org/10.1111/jcpp.13219

49. P.M. Valkenburg, J. Peter, The differential susceptibility to media effects model, Journal of Communication, 63(2) (2013) 221-243. https://doi.org/10.1111/jcom.12024

50. A. Sameroff, The transactional model, in: A. Sameroff (Ed.), The transactional model of child development: How children and contexts shape each other, American Psychological Association, Washington, DC, 2009, pp. 3-22.

https://doi.org/10.1037/11877-001

51. S. Epskamp, C.D. van Borkulo, D.C. van der Veen, M.N. Servaas, A.-M. Isvoranu, H. Riese, A.O.J. Cramer, Personalized network modeling in psychopathology: The importance of contemporaneous and temporal connections, Clinical Psychological Science 6(3) (2018) 416-427. https://doi.org/10.1177/2167702617744325

52. D. McNeish, E.L. Hamaker, A primer on two-level dynamic structural equation models for intensive longitudinal data in Mplus, Psychol Methods 25(5) (2020) 610635. https://doi.org/10.1037/met0000250

53. N. Johannes,., et al., How should we investigate variation in the relation between social media and well-being? PsyArXiv. 2021. 
54. P. M. Valkenburg, Social media use and well-being: What we know and what we need to know. Current Opinion in Psychology, 45, 2022, 101294. 


\section{Figure 1}

Conceptual Illustration of Different Analytical Approaches to Examine the Association Between Social Media Use and Social Capital

Fig. 1a Between-person association

- Aim: Examining the association between individual differences in social capital and social media use

- Method: Individuals are measured once $(\mathrm{t}=1)$

- Example: Individuals who use more social media (on average), experience more social capital as compared to others

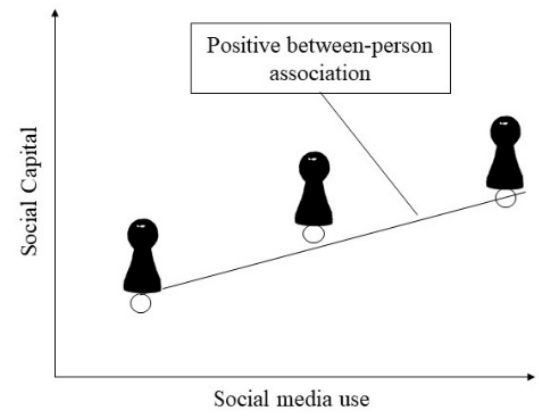

Fig. 1b Within-person association

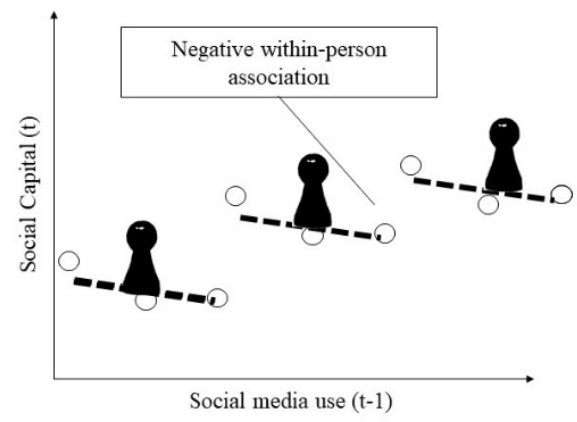

Fig. 1c Person-specific associations

- Aim: Examining how the effects of social media use on intra-individual changes in social capital vary from person to person

- Method: Individuals are repeatedly measured with many measurement occasions across a short time window $(t \geq 50)$

- Example: Individual 8 experiences less social capital, individual $\mathbf{e x p e r i e n c e s ~ m o r e ~}$ social capital, and for no individual change is observed after using social media (t-1)

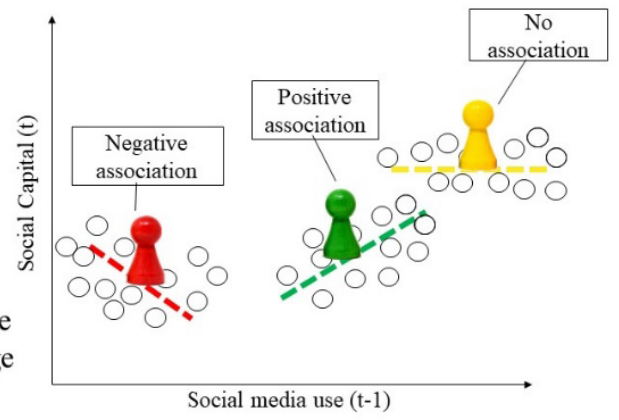


Fig. 1d Bottom-up Approach

Step 1: Examining how many adolescents get richer or poorer in terms of social capital

Step 2: Comparing those who get richer and those who

get poorer on various indicators of initial levels of

social richness and poorness

Positive effect of social

media use on social

Lonely, introvert, non-supported 